\title{
The fifth horseman of tobacco control: personal and organisational involvement
}

In this issue of Tobacco Control, Gregorio ${ }^{1}$ reveals the results of a survey of physicians and dentists in Connecticut (USA), in which respondents were asked about their support of tobacco control policy issues and their personal initiatives in community public health regarding tobacco control. As might be predicted, there was general, broad support for measures to control youth access to tobacco, to educate youth about the dangers of smoking in school curricula, to raise excise taxes on tobacco, and to prohibit tobacco advertising in public places. Physicians were slightly more supportive than dentists of tobacco control policy initiatives.

It is disappointing to note, however, that the respondents' support for changing social norms around tobacco use through policy measures was not matched by their personal willingness to participate actively in measures that could influence such change. Only one in five reported that they educated themselves on counselling patients about tobacco use cessation; even fewer reported activities such as financial contributions to prevention programmes, participation in school-based educational efforts, contact with policy makers to express support for tobacco control measures, signing petitions for tobacco control initiatives, or writing commentaries for local newspapers.

It is a widely held belief among many members of the tobacco control community in the US that there is a lack of active commitment by physicians regarding tobacco control. Indeed, a grant review committee recently convened by a private foundation in the US denied an application with many positive attributes in large part because the key to its success would have meant motivating large numbers of physicians to leave their offices and involve themselves in community tobacco control activities - an obstacle that, for the committee, seemed too difficult to overcome.

Gregorio's survey results should not surprise us. It is only natural that intellectual support of concepts such as control of tobacco use by means of policy change would outpace personal action and involvement. In any activity or cause, whether based in public health, civil rights, or partisan politics, it is always easier to find those willing only to cheer from the sidelines. In any endeavour, change requires action, and people willing to act as agents for change; and we must remember that public health is political.

In recent speeches to tobacco control groups, Michael Pertschuk has outlined "four horsemen" for tobacco control advocates. He points out that four promising areas in tobacco control policy for which consensus support exists include (a) restrictions on youth access to tobacco, (b) increases in tobacco taxes, (c) restrictions on tobacco advertising and promotion, and ( $d$ ) efforts to protect the public from the harmful effects of environmental tobacco smoke (ETS) exposure. As reflected in the responses of physicians and dentists in Connecticut, Pertschuk seems to be accurate about what we are willing to cheer for. To take us to the next phase in this effort, I would suggest a fifth horseman - personal and organisational involvement.

In an editorial written during his tenure as editor of the New York State Fournal of Medicine, Dr Alan Blum noted the success in mobilising public support by animal rights groups and environmental organisations, and speculated that a photograph of a baby seal dying from a tobaccorelated disease would garner a massive public outcry for tobacco control efforts. ${ }^{2}$ Is there an equivalent image that would galvanise health professionals?

Medical and dental societies, public health organisations, and related groups should rally around tobacco control just as Greenpeace has focused on the environment. Organisations that represent the collective thinking and mission of health professionals serve to lay the foundation from which individuals act, whether in patient care or public health matters. For example, the British Medical Association has been a leader for a number of years both in passing tobacco-related policy statements and in lobbying Parliament for changes in policy. Other medical organisations have also begun to see tobacco control as more than of rhetorical importance: the Australian Medical Association, the American Medical Association (AMA), and the Canadian Medical Association have all begun to join the fight in earnest.

Dental societies, at least in the US, have taken on tobacco as a policy issue more recently, which may be reflected in the relative lack of support for tobacco control policies by dentists responding to Gregorio's survey. The dental profession in the US has begun to engage in tobacco control activities through the work of the National Dental Tobacco-Free Steering Committee. Convened in 1989 by the National Cancer Institute, this committee of national public health and private-sector dental organisations serves to promote activities that would lead to a tobaccofree society. Tobacco use intervention, professional collaboration, and tobacco control policy development are key issues for the group. This committee is a model for others in the tobacco control community, and promises to be a major catalyst in bringing the dental profession into the tobacco wars.

As is often the case, organised medicine has taken its share of criticism from tobacco control groups that have broken the trail for them. In Australia, BUGAUP (Billboard Utilising Graffitists Against Unhealthy Promotion); in the US, DOC (Doctors Ought to Care); and in Canada, Physicians for a Smokefree Canada have all served as the conscience regarding tobacco control for their more slow-paced, bureaucratic cousins.

Progress has, happily, taken place. As an example, the work of a few committed members of the AMA House of Delegates and prodding by DOC has produced no less than 84 policy statements on tobacco issues, co-sponsorship of two national "summit" meetings on tobacco control in 1989 and 1993, several tobacco "theme" issues of $\mathcal{F} A M A$, and very fruitful collaboration with governmental health agencies, the major voluntary health associations, and private foundations. Physicians in the US, partly because of a desire to act as examples to the public, now have a cigarette smoking prevalence of only $3 \%{ }^{3}$

There is still a great gap between policy-making and action. Despite several AMA policy pronouncements promoting medical school education about smoking and health, tobacco control curricula in US medical schools are still dependent on whether a faculty member with interest in tobacco issues can steal a bit of time from one of the more traditional, disease-related areas to teach students about the most important determinant of premature 
mortality in this country. Too few American physicians routinely counsel patients about smoking cessation, and the perception persists that the AMA's political lobbying on tobacco control issues is more show than substance.

Individuals committed to create change continue to spark movements, and organisational change. The avantgarde physician-led groups mentioned above have been successful largely because of the effort and force of will shown by their founders: Dr Arthur Chesterfield-Evans in Australia, Dr Mark Taylor in Canada, Dr Blum in the US. Their accomplishments may be intimidating for many physicians, who are cautious creatures by nature, but "ordinary" physicians in practice or in hospitals can exert enormous power. By testifying, for example, at a local city council hearing on youth access to tobacco or ETS protection, they easily discredit the dis-information promulgated by the hired spokespersons for tobacco companies, because physicians and dentists still wear the mantle of respect and authority vested in their professions by the public, especially in smaller cities and towns.

a Picketing tobacco-sponsored sports events may seem too radical for many; however, DOC members across the US have found strong support for such activities by their patients and the community (and have found it fun to ridicule the tobacco industry). Most newspapers welcome editorials and letters from physicians or dentists on tobacco control issues, and educational opportunities about tobacco and its impact on health abound, from the school classroom to the local church or civic club.
I hardly need to reiterate the horrific toll taken in lives, and the economic costs to health delivery systems around the world, due to tobacco use. As more markets open to the transnational tobacco companies, more youth and women will succumb to the lure of this killer. Marlboro is already the world's leading consumer commodity. While recognising that the interaction between doctor or dentist and patient is still enormously important to tobacco control, changing the social norms about tobacco use by means of policy actions such as Pertchuck's "four horsemen" will accelerate the decline in tobacco consumption. Physicians, dentists, and other health care practitioners and the organisations representing them must be in the vanguard of this movement, advocating changes in the status quo regarding tobacco and its place in our world. Too much is at stake for us to be passive participants in this struggle. Our children are counting on us to make a difference.

\section{American Medical Association Chicago, Illinois, USA}

THOMAS P HOUSTON

1 Gregorio DI. Support for tobacco control initiatives among physicians and dentists who treat adolescent patients. Tobacco Control 1994; 3: 208-12.

2 Blum A. If smoking killed baby seals... NY State f Med 1985; 85: 282-5.

3 Nelson DE, Giovino GA, Emont SE, et al. Trends in cigarette smoking among US physicians and nurses. $\mathcal{F} A M A 1994 ; 271$ : 1273-5.

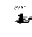

$i_{1}=$

2.

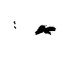

$-$

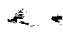

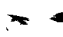

-

$\div$

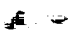

$-4$

$-$

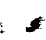

\pm : 